\title{
Queima de biomassa e efeitos sobre a saúde*
}

\author{
Biomass burning and health effects

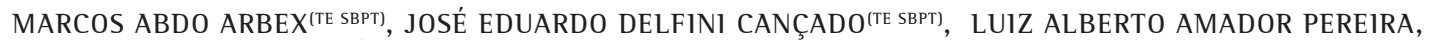 \\ ALFÉSIO LUIS FERREIRA BRAGA**, PAULO HILÁRIO DO NASCIMENTO SALDIVA
}

A primeira idéia que se forma na mente das pessoas e do pesquisador é associar a poluição do ar aos grandes centros urbanos, com a imagem de poluentes sendo eliminados por veículos automotores ou pela chaminé de suas fábricas. Entretanto, uma parcela considerável da população do planeta convive com uma outra fonte de poluição, que atinge preferencialmente os países em desenvolvimento: a queima de biomassa. Este artigo tem como objetivo chamar a atenção do pneumologista, da comunidade e das autoridades para os riscos à saúde da população exposta a essa fonte geradora de poluentes, seja em ambientes internos, seja em ambientes abertos. 0 presente trabalho caracteriza as principais condições que levam à combustão de biomassa, como a literatura tem registrado os seus efeitos sobre a saúde humana, discutindo os mecanismos fisiopatológicos envolvidos, e finaliza com a apresentação de dois estudos recentes que enfatizam a importância da queima de um tipo específico de biomassa, a palha da cana-de-açúcar, prática comum no interior do Brasil, e sua interferência no perfil de morbidade respiratória da população exposta .
The first thought that comes to mind concerning air pollution is related to urban centers where automotive exhausts and the industrial chimneys are the most important sources of atmospheric pollutants. However a significant portion of the earth's population is exposed to still another source of air pollution, the burning of biomass that primarily affects developing countries. This review article calls the attention of lung specialists, public authorities and the community in general to the health risks entailed in the burning of biomass, be it indoors or outdoors to which the population is exposed. This review describes the main conditions that lead to the burning of biomass and how the literature has recorded its effects on human health discussing the psychopathological mechanisms. Finally two recent studies are presented that emphasize an important type of biomass burning that of the sugar cane straw. This is a common practice in several regions of Brazil changing the respiratory morbidity standards of the population exposed.

J Bras Pneumol 2004; 30(2) 158-175

Descritores: Biomassa, poluição do ar, cana-de-açúcar, fumaça, queima de vegetação, doenças respiratórias.
Key words: air pollution, biomass, sugar cane, smoke, vegetation fires, respiratory disease.

\footnotetext{
* Trabalho realizado no laboratório de Poluição Atmosférica Experimental da Faculdade de Medicina da Universidade de São Paulo (FMUSP).

* Programa de Pediatria Ambiental da Faculdade de Medicina da Universidade Santo Amaro, SP.

Este estudo foi financiado pelo LIM05-FMUSP e UNISA.

Endereço para correspondência: Av. Dr. Arnaldo, 455, $1^{\circ}$ Andar, Sala 108, Cerqueira César, CEP 01246-903, São Paulo, SP. Tel: (16) 236-5228. E-mail: arbexma@techs.com.br.

Recebido para publicação, em 12/9/03. Aprovado, após revisão, em 12/2/04.
} 


\section{INTRODUÇÃO}

Desde o início do século passado, estudos na literatura médica têm documentado uma significativa associação entre poluição atmosférica decorrente da emissão de combustiveis fósseis e aumento de morbi-mortalidade em humanos nos paises desenvolvidos. Esses efeitos foram observados inclusive para níveis de poluentes no ar considerados como seguros para a saúde da população exposta ${ }^{(1)}$. Entretanto, poucos estudos voltavam-se para os efeitos deletérios produzidos pela queima de biomassa (qualquer matéria de origem vegetal ou animal utilizada como fonte de energia). Em 1985, um boletim da Organização Mundial da Saúde (OMS) (2) questionava qual seria a gravidade e a extensão dos danos produzidos pela poluição do ar em conseqüência da combustão de biomassa em áreas rurais dos países em desenvolvimento.

A incineração de biomassa é a maior fonte doméstica de energia nos países em desenvolvimento ${ }^{(3)}$. Aproximadamente metade da população do planeta, e mais de 90\% das casas na região rural dos países em desenvolvimento, permanecem utilizando energia proveniente da queima de biomassa, na forma de madeira, carvão, esterco de animais ou resíduos agrícolas, o que produz altos indices de poluição do ar em ambientes internos, onde permanecem as mulheres que cozinham e as crianças. Essa situação provoca um aumento do risco de infecção respiratória, a maior causa de mortalidade infantil nos países em desenvolvimento ${ }^{(3,4)}$.

A queima deliberada ou acidental de vegetação, apesar do grande avanço tecnológico experimentado pela humanidade, ou até justamente por causa dele, torna-se por vezes incontrolada, atingindo grandes extensões de florestas, savanas ou outras vegetações menos densas. 0 fogo é um problema crescente no que resta das florestas tropicais do planeta e a poluição devida à fumaça gerada tem um importante impacto sobre a saúde das populações expostas. Esse impacto inclui aumento de mortalidade, de admissões hospitalares, de visitas à emergência e de utilização de medicamentos, devidas a doenças respiratórias e cardiovasculares, além de diminuição da função pulmonar ${ }^{(4)}$.

Apesar dos anos de estudos científicos e da atenção da mídia em relação ao desmatamento e
Siglas e abreviaturas utilizadas neste trabalho:

BC- Black Carbon

CETESB - Companhia de Tecnologia de Saneamento Ambiental

CVF- Capacidade vital forçada

DPOC- Doença pulmonar obstrutiva crônica

EPA - Environmental Protection Agency (USA)

$\mathrm{FEF}_{25-75 \%}$ - Fluxo expiratório forçado a $25 \%$ - 75\% da CVF 1C95\%- Intervalo de confiança para 95\% de probabilidade IVAS- Infecção de vias aéreas superiores

IVAl- Infecção de vias aéreas inferiores

LPAE - Laboratório de Poluição Atmosférica Experimental

OMS - Organização Mundial da Saúde

PM - Material particulado

$\mathrm{PM}_{10}$ - Material particulado com diâmetro aerodinâmico menor que $10 \quad 1 / 4 \mathrm{~m}$

$\mathrm{PM}_{2,5}$ - Material particulado com diâmetro aerodinâmico menor que $2,51 / 4 \mathrm{~m}$

OR- Razão de chance (Odds ratio)

TSP - Partículas totais em suspensão

VEF- Volume expiratório forçado

VEF - Volume expiratório forçado no primeiro segundo

WHO - World Health Organization

às queimadas, acidentais ou intencionais, a incidência e o efeito dos incêndios florestais têm sido ignorados. As grandes queimadas em Bornéu (1983 e 1997), Tailândia (1997), Indonésia (1997), Roraima (1997-1998), Mato Grosso (1998) e Pará (1998) despertaram a atenção para o problema, mas as medidas tomadas para prevenir ou controlar tais incêndios ainda são insuficientes ${ }^{(5)}$.

\section{O processo de combustão, seus produtos e suas repercussões fisiopatológicas}

A combustão é um processo químico pelo qual um material reage rapidamente com o oxigênio do ar produzindo luz e calor intenso e, no caso da biomassa, se faz em três estágios: ignição (ignition), combustão com chama (flaming), e combustão com ausência de chama (smoldering).

Cerca de $80 \%$ da combustão de biomassa ocorre nos trópicos. Ela é a maior fonte de produção de gases tóxicos, material particulado e gases do efeito estufa no planeta ${ }^{(6)}$, influencia a química e a física atmosférica, produz espécies químicas que mudam significativamente o $\mathrm{pH}$ da água da chuva ${ }^{(7,8)}$, e afeta o balanço térmico da atmosfera pela interferência na quantidade de radiação solar refletida para o espaço ${ }^{(9,10)}$. A Tabela 1 apresenta uma descrição sucinta dos principais poluentes gerados no processo de queima da biomassa.

Como pode ser observado na Tabela 2, estudos 
mostram que a exposição dos seres vivos a muitos desses elementos pode produzir, a curto e a longo prazo, efeitos deletérios à saúde.

Dentre esses elementos, o material particulado decorrente da combustão de biomassa, seja em ambientes internos, seja em ambientes abertos, é o poluente que apresenta maior toxicidade e que tem sido mais estudado. Ele é constituído em seu maior percentual (94\%) por partículas finas e ultrafinas (Figura 1), ou seja, partículas que atingem as porções mais profundas do sistema respiratório, transpõem a barreira epitelial, atingem o interstício pulmonar e são responsáveis pelo desencadeamento do processo inflamatório (11-13) (Figura 2). Shi et al.(14) sugerem que os efeitos adversos do material particulado à saúde podem ser atribuídos à produção de agentes oxidantes intracelulares, que seriam a resposta inicial e que agiriam como um fator estimulante da inflamação, como mostra a Figura 3. Turn et al. (15) mostraram que as queimadas emitem poluentes que atuam não só localmente como também podem afetar regiões distantes de onde foram originadas, através do transporte a longas distâncias, o que aumenta as proporções do impacto sobre os indivíduos.

TABELA 1

Principais poluentes proveniente da queima de biomassa

\begin{tabular}{|c|c|c|c|}
\hline Compostos & Exemplos & Fonte & Notas \\
\hline \multirow[t]{3}{*}{ Partículas } & $\begin{array}{l}\text { Partículas } \\
\text { inaláveis }\left(\mathrm{PM}_{10}\right)\end{array}$ & $\begin{array}{l}\text { Condensação após combustão } \\
\text { de gases; combustão } \\
\text { incompleta de material } \\
\text { inorgânico; fragmentos } \\
\text { de vegetação e cinzas }\end{array}$ & $\begin{array}{l}\text { Partículas finas e grossas. } \\
\text { Partículas grossas não } \\
\text { são transportadas e } \\
\text { contêm principalmente } \\
\text { cinzas e material do solo }\end{array}$ \\
\hline & Partículas respiráveis & $\begin{array}{l}\text { Condensação após combustão } \\
\text { de gases; combustão } \\
\text { incompleta de material } \\
\text { orgânico. }\end{array}$ & $\begin{array}{l}\text { No caso de fumaça } \\
\text { proveniente da } \\
\text { queima de biomassa } \\
\text { comporta-se como } \\
\text { partículas finas }\end{array}$ \\
\hline & Particulas finas $\left(\mathrm{PM}_{2,5}\right)$ & $\begin{array}{l}\text { Condensação por combustão } \\
\text { de gases; combustão } \\
\text { incompleta de material } \\
\text { orgânico }\end{array}$ & $\begin{array}{l}\text { Transportadas através de } \\
\text { longas distâncias. } \\
\text { Produção primária e } \\
\text { secundária }\end{array}$ \\
\hline \multirow[t]{2}{*}{ aldeídos } & acroleína & $\begin{array}{l}\text { Combustão incompleta de } \\
\text { material orgânico }\end{array}$ & \\
\hline & formaldeido & $\begin{array}{l}\text { Combustão incompleta de } \\
\text { material orgânico }\end{array}$ & \\
\hline \multirow[t]{3}{*}{$\begin{array}{l}\text { Ácidos } \\
\text { inorgânicos }\end{array}$} & $\begin{array}{l}\text { Monóxido de } \\
\text { carbono (CO) }\end{array}$ & $\begin{array}{l}\text { Combustão incompleta de } \\
\text { material orgânico }\end{array}$ & $\begin{array}{l}\text { Transportado através de longas } \\
\text { distancias }\end{array}$ \\
\hline & ozônio & $\begin{array}{l}\text { Produto secundário do óxidos } \\
\text { de nitrogênio e } \\
\text { hidrocarbonetos }\end{array}$ & $\begin{array}{l}\text { Presente somente adiante do } \\
\text { fogo, transportado } \\
\text { através de longas distâncias }\end{array}$ \\
\hline & $\begin{array}{l}\text { Dióxido de } \\
\text { nitrogênio }\left(\mathrm{NO}_{2}\right)\end{array}$ & $\begin{array}{l}\text { Oxidação em altas } \\
\text { temperaturas do } \\
\text { nitrogênio do ar }\end{array}$ & $\begin{array}{l}\text { Espécies reativas; a } \\
\text { concentração diminui } \\
\text { com a distância do fogo }\end{array}$ \\
\hline Hidrocarbonetos & benzeno & $\begin{array}{l}\text { Combustão incompleta de } \\
\text { material orgânico }\end{array}$ & $\begin{array}{l}\text { Transporte local; também } \\
\text { reage com outras formas de } \\
\text { aerossol orgânico }\end{array}$ \\
\hline $\begin{array}{l}\text { Hidrocarbonetos } \\
\text { aromáticos } \\
\text { policíclicos(PAHs) }\end{array}$ & Benzopireno (BaP) & $\begin{array}{l}\text { Condensação após } \\
\text { combustão de gases; } \\
\text { combustão incompleta de } \\
\text { material orgânico }\end{array}$ & $\begin{array}{l}\text { Compostos específicos que } \\
\text { variam de acordo com a } \\
\text { composição da biomassa }\end{array}$ \\
\hline
\end{tabular}




\section{Queima de biomassa em ambientes internos e agravos à saúde}

A poluição do ar em ambientes internos existe desde os tempos pré-históricos, quando os humanos iniciaram sua movimentação para regiões com clima temperado, há aproximadamente 200 mil anos atrás. 0 clima mais frio provocou a necessidade de uso de abrigos e cavernas e a utilização de fogo para aquecimento, preparo de alimentos e iluminação. Ironicamente, o fogo, que foi o que possibilitou aos humanos aproveitar os benefícios dos abrigos, provocava uma exposição a altos níveis de poluição, como ficou evidenciado pelo carvão encontrado em cavernas pré-históricas.
Fuligens encontradas em cavernas no sul da África indicam que a raça humana utiliza o fogo há 1,5 milhões de anos ${ }^{(16)}$

Os efeitos sobre a saúde, decorrentes da exposição por longos períodos à fumaça produzida pela queima de biomassa em ambientes fechados, têm sido associados com infecções respiratórias agudas em crianças, doença pulmonar obstrutiva crônica (DPOC), pneumoconiose, catarata e cegueira, tuberculose pulmonar e efeitos adversos na gestação. Esses efeitos foram bem documentados em países em desenvolvimento, onde mulheres acompanhadas de seus filhos permanecem várias horas cozinhando em fogões

TABELA 2

Mecanismos pelos quais os poluentes presentes na fumaça gerada pela queima de biomassa em domicílios podem aumentar o risco de doenças.

\begin{tabular}{|c|c|c|}
\hline Poluentes & Mecanismos & Efeitos Potenciais Sobre A Saúde \\
\hline $\begin{array}{l}\text { Material particulado: } \\
\text { partículas menores } \\
\text { que } 10 \mu \text {, e sobretudo } \\
\text { as menores } \\
\text { que } 2,5 \mu \text { de diâmetro } \\
\text { aerodinâmico }\end{array}$ & $\begin{array}{l}\text { Agudo: irritação, inflamação e aumento } \\
\text { de reatividade brônquica. } \\
\text { Redução do transporte muco-ciliar } \\
\text { Redução das respostas dos macrófagos } \\
\text { e (?) redução da imunidade local. } \\
\text { (?) Reação fibrótica. } \\
\text { Descontrole autonômico, atividade pró- } \\
\text { coagulante, stress oxidativo }\end{array}$ & $\begin{array}{l}\text { Sibilos, exacerbação de crises de } \\
\text { asma brônquica. } \\
\text { lnfecções respiratórias. } \\
\text { DPOC } \\
\text { Exacerbações de DPOC }\end{array}$ \\
\hline Monóxido de carbono & $\begin{array}{l}\text { Produção de carboxihemoglobina com } \\
\text { conseqüente redução da absorção de } \\
\mathrm{O}_{2} \text { por órgãos vitais etambém prejuízo do } \\
\text { desenvolvimento do feto }\end{array}$ & $\begin{array}{l}\text { Recém natos de baixo peso } \\
\text { Aumento de mortes fetais }\end{array}$ \\
\hline Dióxido de nitrogênio & $\begin{array}{l}\text { Exposição aguda aumenta a reatividade } \\
\text { brônquica } \\
\text { Exposição crônica aumenta a suscetibilidade a } \\
\text { infecções respiratórias bacterianas e virais }\end{array}$ & $\begin{array}{l}\text { Sibilos e exacerbação de asma } \\
\text { brônquica } \\
\text { lnfecções respiratóriasDiminuição da } \\
\text { capacidade pulmonar em crianças }\end{array}$ \\
\hline Dióxido de enxofre & $\begin{array}{l}\text { Exposição aguda aumenta a reatividade } \\
\text { brônquica } \\
\text { Exposição crônica: é difícil dissociar dos efeitos } \\
\text { do material particulado }\end{array}$ & $\begin{array}{l}\text { Sibilos e exacerbação de asma } \\
\text { brônquica } \\
\text { Exacerbação de DPOC, DCV } \\
\text { (?) aumento de suscetibilidade a }\end{array}$ \\
\hline Formaldeido & $\begin{array}{l}\text { lrritação de vias respiratórias altas } \\
\text { (?) Aumento de sensibilização a alergenos. }\end{array}$ & $\begin{array}{l}\text { infecções } \\
\text { (?) pode agravar a asma brônquica. }\end{array}$ \\
\hline Benzopireno & $\begin{array}{l}\text { Carcinogênico (uma das substancias } \\
\text { carcinogênicas no carvão e na fumaça } \\
\text { da biomassa). }\end{array}$ & $\begin{array}{l}\text { Câncer de pulmão } \\
\text { Câncer de boca, nasofaringe e laringe }\end{array}$ \\
\hline Fumaça da biomassa & $\begin{array}{l}\text { Absorção das toxinas no interior da lente, } \\
\text { causando mudanças oxidativas. }\end{array}$ & Catarata \\
\hline
\end{tabular}

DPOC: doença pulmonar obstrutia crônica; 
em locais sem abertura para eliminar a fumaça para o exterior. Enquanto nos países desenvolvidos a DPOC está relacionada principalmente ao tabagismo, nas regiões em desenvolvimento, onde o tabagismo no sexo feminino não é freqüente, estudos epidemiológicos transversais e casocontrole indicam que a exposição à fumaça proveniente da queima de biomassa é o principal fator de risco para DPOC. Padmavati et al. ${ }^{(17,18)}$, na Índia, mostraram uma relação entre exposição aos poluentes em ambientes internos e DPOC conduzindo a o cor pulmonale. $\mathrm{Na}$ índia, a incidência de cor pulmonale crônico é similar entre homens e mulheres, apesar do fato de que 75\% dos homens e somente $15 \%$ das mulheres são tabagistas. Análises comparando a incidência de cor pulmonale crônico em mulheres e em homens revelaram que a patologia era mais comum em mulheres jovens e a média de idade das pacientes era 10 a 15 anos menor que a média da idade dos pacientes do sexo masculino. Em 18 necropsias em mulheres que nunca fumaram, mas estiveram expostas a poluentes provenientes da combustão de biomassa, todas apresentaram enfisema pulmonar, 11 bronquiectasias, 5 bronquite crônica, e 2 apresentaram tuberculose ${ }^{(18)}$. A prevalência de cor pulmonale crônico era menor nos estados do sul em relação aos estados do norte, fato que os autores atribuíram a uma maior ventilação no interior das residências da região sul, área com temperaturas mais altas no verão e que não necessitavam de aquecimento no inverno menos rigoroso que o da região norte. Estudo subseqüente confirmou esses achados ${ }^{(28,19)}$. Máster ${ }^{(20)}$ avaliou habitantes de vilas localizadas nas regiões montanhosas da Nova Guiné que utilizavam a queima de biomassa para aquecimento na maioria das noites do ano. Dos indivíduos entrevistados com idade maior que 40 anos, 78\% apresentavam tosse, diminuição difusa do murmúrio vesicular, estertores crepitantes e distúrbio ventilatório, principalmente obstrutivo. Estudo anatomopatológico com amostras provenientes de indivíduos expostos mostrou enfisema centrolobular, espessamento pleural, fibrose pulmonar, hipertrofia de glândulas mucosas e deposição de pigmento antracótico. Anderson, na Nova Guiné(21,22), encontrou em adultos com idade superior a 45 anos uma alta prevalência de sintomas respiratórios, em proporções semelhantes em homens e mulheres, e mostrou que em 20\%

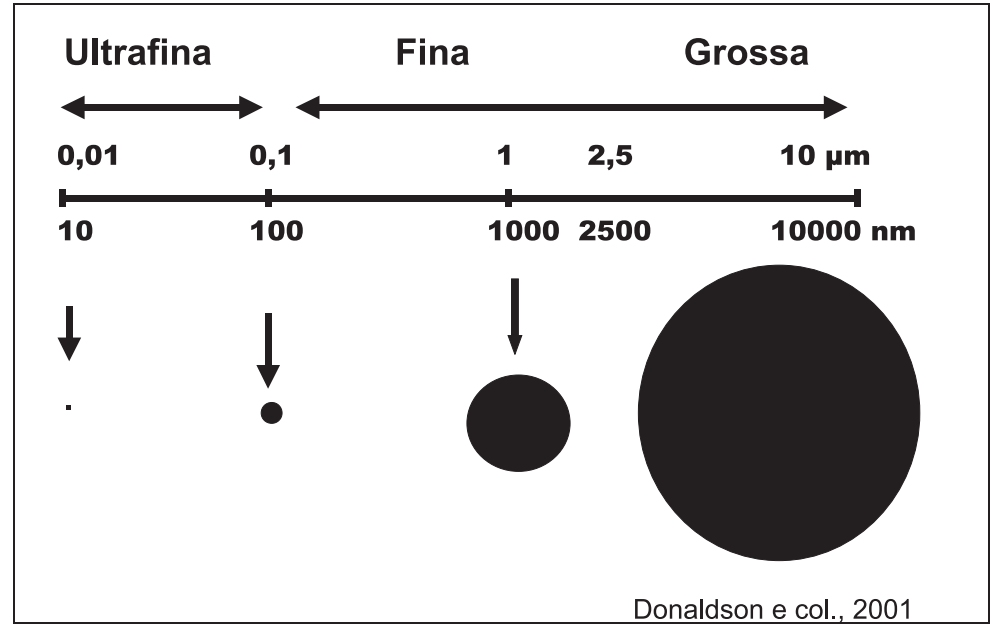

Figura 1. Partículas grossa, fina e ultrafina

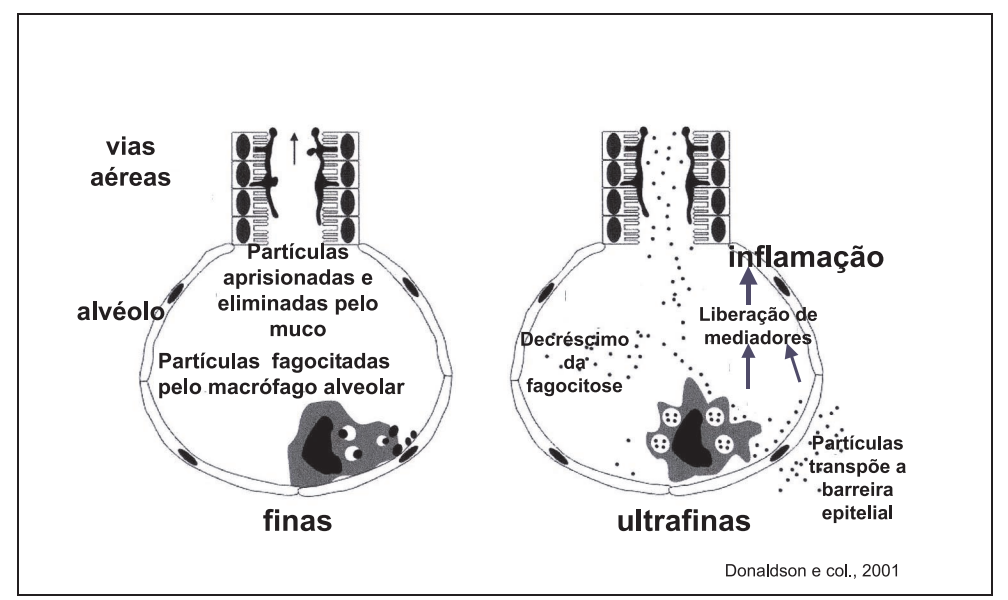

Figura 2. Representação esquemática dos eventos hipotéticos após exposição a partículas ultrafinas (direita) quando comparado com a exposição a partículas finas (esquerda). 0 elemento essencial à resposta ultrafina é um grande número de partículas fora e dentro dos macrófagos. Há liberação de mediadores pelo macrófago e pela célula epitelial devido à ativação de vias mediadas por stress oxidativo, que conduzem à inflamação

dos homens e 10\% das mulheres havia obstrução ao fluxo aéreo, com uma relação entre o volume expiratório forçado no primeiro segundo e a capacidade vital forçada $\left(\mathrm{VEF}_{1} / \mathrm{CVF}\right.$ ) menor que $60 \%$. 0 autor chamou a atenção ainda para o fato de que indivíduos com quadro clínico compatível com DPOC apresentavam fibrose pulmonar intersticial difusa e bronquiectasias. No Nepal, a 


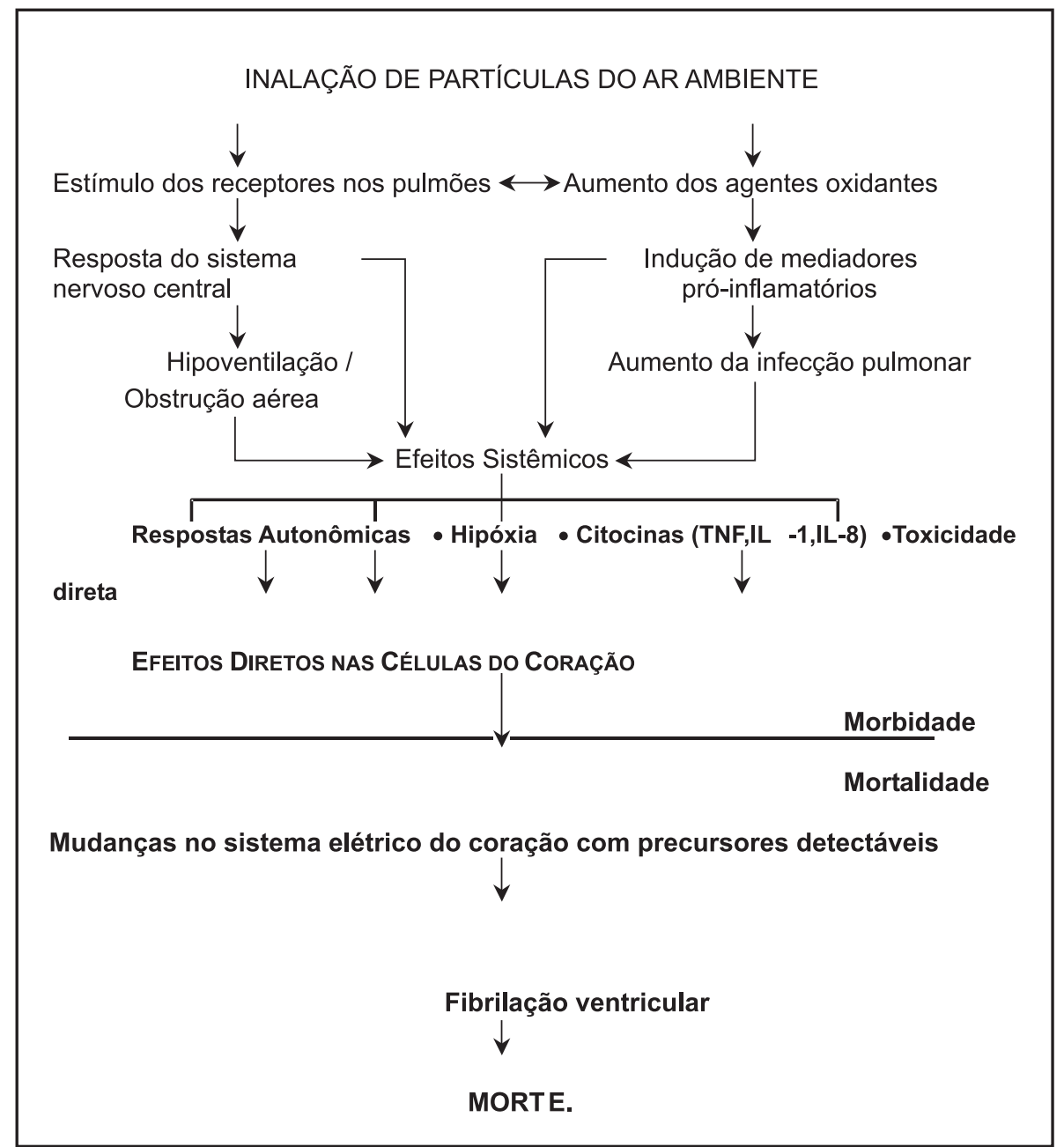

Figura 3. Mecanismos hipotéticos pelos quais a inalação de partículas pode levar à morte

prevalência de bronquite crônica é similar entre homens e mulheres $(18,9 \%)$, apesar de o tabagismo ser substancialmente mais comum entre os homens ${ }^{(23,24)}$. A prevalência de bronquite crônica é também considerável em Ladakh, Índia e no Paquistão, onde a incidência de mulheres fumantes é mínima ${ }^{(25,26)}$. Estudos caso-controle realizados em hospitais demonstraram que indivíduos sujeitos à exposição à fumaça proveniente da combustão de biomassa apresentam mais freqüentemente quadro de obstrução ao fluxo aéreo, em relação a grupos controles $^{(27-29)}$. Esse fato se repete em estudos realizados em comunidades ${ }^{(19,30,31)}$. Os estudos realizados em hospitais mostraram obstrução grave em associação positiva e significante com o nível de exposição aos poluentes, com razão de chance (OR) que variava entre 1,8 e 9,7, enquanto que um estudo realizado na comunidade mostrou OR de $2,5^{(31)}$. Regalado et al. ${ }^{(30)}$, no México, mostraram que a queima da biomassa como fonte de energia estava associada a um decréscimo de 4\% na relação $\mathrm{VEF}_{1} / \mathrm{CVF}$ nos indivíduos expostos e que uma concentração de $1000 \mathrm{\mu g} / \mathrm{m}^{3}$ de material particulado nas cozinhas estava associada a uma redução de $2 \%$ no $\mathrm{VEF}_{1}$. Na Índia, a população que utilizava biomassa como fonte de energia apresentava CVF menor em relação àquela que utilizava gás ou querosene ${ }^{(19)}$. Pandey et al. ${ }^{(23,24)}$ 
relataram uma relação exposição-resposta com diminuição da VEF, e da CVF à medida que aumentava o número de horas de exposição aos poluentes. Menezes et al. ${ }^{(32)}$, em estudo transversal realizado em área urbana no sul do Brasil para determinar a prevalência de bronquite crônica e a sua relação com fatores de risco, entrevistaram 1053 indivíduos com idade acima de 40 anos e encontraram uma associação significante entre a doença e altos níveis de poluição em ambientes internos.

A exposição a poluentes nos estudos apresentados foi usualmente estimada por questionários que avaliavam as horas de exposição diária e o número de anos de exposição. Um estudo caso-controle considerou a medida hora-anos: anos de exposição multiplicado pela média de horas de exposição diária. 0 risco de bronquite crônica isolada e de bronquite crônica associada a obstrução crônica de vias aéreas aumentou linearmente com as hora-anos de exposição à fumaça de biomassa. A OR para exposição superior a 200 hora-anos comparada à não exposição era de 15, com intervalo de confiança (IC) de 95\% 5.6-40, para bronquite crônica e 75 (1C 95\%, 18306) para bronquite crônica associada a obstrução crônica de vias aéreas ${ }^{(29)}$. Poucos estudos quantificaram o nível do material particulado nas cozinhas, mas estes confirmaram uma alta concentração desse poluente ${ }^{(33,30,31)}$. Narboo ${ }^{(25)}$ demonstrou a relação entre o número de horas dispendido na cozinha e o nível individual do monóxido de carbono exalado. Essas e outras evidências levaram à inclusão da poluição em ambientes internos por combustão de biomassa na relação de fatores de risco para o desenvolvimento da DPOC apresentada na Global Strategy for The Diagnosis, Management, and Prevention of Chronic Obstrutive Lung Disease (GOLD).

Em 1991, Narboo et al. ${ }^{(25,34)}$ mostraram em Ladakh, Índia, indivíduos com quadro clínicoradiológico compatível com pneumoconiose. No entanto, não havia indústrias ou minas no local. Dois fatores foram aventados para explicar o desenvolvimento da patologia respiratória: exposição à poeira proveniente das tempestades de areia, comuns na primavera, e exposição ao material particulado proveniente de combustão da biomassa utilizada para aquecer as residências, desprovidas de ventilação, para enfrentar o rigoroso frio da região. Investigações clínicas e radiológicas ${ }^{(35)}$ em 449 habitantes de três vilas sujeitas a tempestades de areia com intensidades leve, moderada e grave mostraram prevalências de pneumoconiose de 2,0\%, 20,1\% e 45,3\%, respectivamente. Os radiogramas de tórax mostravam características radiológicas indistinguiveis dos padrões radiológicos encontrados em individuos portadores de pneumoconiose que trabalhavam em minas ou indústrias. A concentração de poeira em cozinhas sem chaminé variava entre 3,22 e $11,30 \mathrm{mg} / \mathrm{m}^{3}$, com uma média de $7,50 \mathrm{mg} / \mathrm{m}^{3}$. Estudos estatísticos detalhados estabeleceram que a ocorrência de pneumoconiose era conseqüência não só das tempestades de areia, como também da exposição aos produtos originados pela queima da biomassa, e da idade. Outras duas doenças comumente associadas à exposição ocupacional, a antracose e a fibrose pulmonar intersticial difusa, têm sido encontradas freqüentemente em necropsias de pacientes sujeitos à exposição à fumaça de biomassa em ambientes internos ${ }^{(36,37)}$.

A infecção respiratória aguda de vias aéreas inferiores (IRVI) é a mais importante causa de mortalidade em crianças com idade abaixo de cinco anos, provocando aproximadamente 2 milhões de mortes anualmente nessa faixa etária. Dezesseis estudos epidemiológicos, sendo onze tipo caso-controle e cinco de coorte, realizados nos últimos vinte anos, em paises em desenvolvimento, mostraram uma associação entre exposição à poluição proveniente da queima da biomassa em ambientes internos e infecções respiratórias agudas de vias aéreas inferiores em crianças. Para caracterizar a IVRI foram utilizados critérios da OMS e/ou evidências radiológicas, e em quase todos os estudos foi avaliada a intensidade da exposição, incluindo o tipo de fogão e de combustível ${ }^{(38-46)}$, se as crianças permaneciam em contato com a fumaça durante o preparo de alimentos ${ }^{(47,48)}$, e se as mães carregavam os filhos nas costas enquanto cozinhavam $^{(49-51)}$. Armstrong e Campbell(50), por exemplo, mostraram que o risco de pneumonia em associação com a exposição à fumaça estava aumentado nas meninas, mas não nos meninos. Os autores sugerem que a diferença é conseqüência da maior exposição das meninas e não em virtude 
de diferenças biológicas entre os sexos. No mais recente estudo sobre o tema, Ezzatti e Kammen ${ }^{(52,53)}$ acompanharam 345 crianças na região rural do Quênia (93 com idade menor que cinco anos) em 55 residências em ranchos de gado, que utilizavam biomassa como fonte de energia em fogões sem chaminés. Os autores avaliaram a exposição individual de adultos e crianças e combinaram-na com uma avaliação de sintomas pesquisados semanalmente, utilizando os critérios da OMS para IVRI. Este foi o primeiro estudo a avaliar a relação entre exposição a particulados e incidência de IVRI em crianças (menores que cinco anos) e adultos. Foi altamente significativo o aumento do risco de doença relacionada a altos níveis de exposição. Os autores não ajustaram os resultados para a variável nível socioeconômico. A incidência de IVRI nas crianças deste estudo foi consideravelmente mais alta, quando comparada a estudos prévios que avaliaram populações similares. Detalhada revisão do tema foi publicada por Smith et al. ${ }^{(5)}$, que concluíram que a relação entre a exposição à fumaça da combustão de biomassa e a IVRl pode ser considerada como causal. Entretanto, o risco quantitativo ainda não está bem caracterizado.

Em um único estudo que relacionou mortalidade perinatal (natimortos e mortes na primeira semana de vida) com a queima de biomassa, foi encontrada uma associação (OR de 1,5 IC 95\%: 1,0-2,1 p =0,05), com ajuste para uma ampla variedade de fatores, apesar de a exposição não ter sido diretamente quantificada. Todavia, o achado, com uma significância estatística marginal, é semelhante aos estudos com poluição atmosférica a céu aberto ${ }^{(55)}$.

Estudo conduzido na Guatemala mostrou que o peso dos recém-natos provenientes de residências que utilizavam biomassa como combustivel era $63 \mathrm{~g}$ (1C 95\%: 0,4-127, p=0,049) menor em relação aos recém-natos provenientes de residências que utilizavam combustiveis "limpos". Esta estimativa foi ajustada para fatores confundidores, mas a exposição aos poluentes não foi diretamente quantificada ${ }^{(56)}$.

Os trabalhos que relacionam combustão de biomassa em ambientes internos e asma são conflitantes. Estudo caso controle em escolares em Nairobi, Quênia, mostrou um aumento do número de indivíduos asmáticos em residências em que havia exposição à fumaça de madeira ${ }^{(57)}$. Estudo caso controle avaliando indivíduos entre onze e dezessete anos, realizado no Nepal, e utilizando o ISAAC (International Study of Asthma and Allergies in Children) encontrou OR de 1,81 (1.04-4.8) para asma ao comparar os indivíduos que utilizavam biomassa como fonte de energia e os que usavam gás ou querosene ${ }^{(58)}$. Estudo transversal avaliando 1058 indivíduos entre quatro e seis anos na Guatemala, também utilizando o ISAAC, encontrou OR de 1.81 (IC 95\%; 1,04-3,12) para sibilos em qualquer época e OR de 2.35 (IC 95\%; 1,08-5,13) para sibilos nos últimos doze meses da avaliaçã $0^{(59)}$, entre crianças expostas à queima de biomassa. Todavia, há estudos em que a mesma associação não foi encontrada ${ }^{(26,33,60)}$.

Estudos recentes sugerem uma associação da queima da biomassa em ambientes internos e tuberculose pulmonar(61-63). Essa associação, se confirmada, representa uma substancial implicação na saúde publica. A exposição à fumaça originada pela queima da biomassa poderia explicar a significativa diferença de prevalência da tuberculose encontrada na índia entre as zonas rural e urbana, uma vez que 59\% dos casos de tuberculose são provenientes da zona rural, onde a utilização de biomassa como combustivel é maior, e 23\% dos casos provenientes da zona urbana. A exposição ambiental ao material particulado pode ser um potencializador do binômio miséria/tuberculose, até este momento explicado somente pela má nutrição, aglomeração de pessoas e acesso inadequado aos serviços de saúde.

A Índia tem o maior número de indivíduos cegos em relação a qualquer outro país do planeta. Além disso, um em cada três episódios de catarata do planeta ocorre na índia. A catarata é responsável por 80\% dos casos de cegueira naquele país. Irritação ocular, hiperemia conjuntival, e lacrimejamento são sinais e sintomas universalmente relatados em conseqüência de exposição à fumaça, mas podem ser alterações preliminares capazes de no futuro conduzirem à cegueira $^{(64)}$. Uma análise de aproximadamente 170 mil indivíduos na índia mostrou um OR de 1,32 (1C 95\%; 1,16-1,50) quando avaliou cegueiras completas ou parciais, comparando pacientes que utilizavam preferencialmente biomassa e pacientes que utilizavam outros tipos de combustível, após 
analisar as condições sócio-econômicas, condições de residência, e variáveis geográficas. Porém não foram avaliados tabagismo e estado nutricional ${ }^{(65)}$.

Até o presente momento, os dados coletados não indicam associação entre o risco de câncer e altos níveis de exposição à fumaça da queima de biomassa. Apesar da fumaça proveniente desse processo ser potencialmente carcinogênica, ainda assim seu poder carcinogênico é menor do que a fumaça proveniente da queima dos combustíveis de veículos automotivos(16).

Os estudos abordando poluição do ar em ambientes internos e seus efeitos sobre a saúde, nos países em desenvolvimento, evidenciaram uma associação importante, apesar de apresentarem limitações metodológicas, como por exemplo: falta de uma melhor determinação da exposição à poluição; caráter observacional dos estudos; e elementos confundidores, via de regra, não avaliados adequadamente. Mas apesar das limitações desses estudos epidemiológicos, a evidência da relação causal entre a poluição do ar em ambientes internos e a DPOC e a IVRI é consistente, especialmente quando vista em conjunto com os conhecimentos prévios adquiridos em relação à poluição tabágica e à poluição atmosférica urbana (não esquecendo as diferentes composições dos poluentes), e com as evidências dos estudos em animais.

Diversos estudos realizados nos Estados Unidos da América focalizaram a relação entre queima de madeira em lareiras e sintomas e/ou medidas de função pulmonar. A maioria dos estudos concentrou-se em crianças com menos de cinco anos devido à maior susceptibilidade desse grupo etário, decorrente de um menor volume pulmonar e do incompleto desenvolvimento de seu sistema imune. Além disso, a ausência de tabagismo ativo e a falta de exposição ocupacional não atuariam como fatores de confusão nesse grupo. A Tabela $3^{(66-72)}$ apresenta os estudos que estudaram o problema de forma mais consistente em ambientes internos. Outros estudos (Tabela 4) ${ }^{\text {(73- }}$ 78) avaliaram os efeitos sobre a saúde em comunidades em que a fumaça da queima de madeira contribui para o aumento da poluição, porém não é a única fonte de material particulado na atmosfera.

A fumaça produzida pela queima de biomassa em ambientes internos interfere no mecanismo muco-ciliar e diminui as propriedades antibacterianas dos macrófagos pulmonares, os quais têm diminuído seu poder de fagocitose ${ }^{(79,80)}$.

Dois estudos toxicológicos em animais sugerem que a exposição à fumaça de madeira pode conduzir a um aumento da suscetibilidade a infecções respiratórias. Em um estudo financiado pela Agência de Proteção Ambiental dos Estados Unidos da América (USEPA), Selgrade comparou o efeito da exposição a um aerosol com Streptococcus zooepidemicus, agente que causa infecção respiratória grave, sobre três grupos de ratos que foram previamente expostos a uma das três situações: ar puro, poluentes gerados a partir da queima de óleo de caldeira, ou poluentes gerados a partir da queima de madeira. Duas semanas após a exposição, 5\% dos ratos expostos ao ar puro ou à fumaça do óleo de caldeira morreram enquanto que entre os ratos expostos à fumaça da queima da madeira, a mortalidade foi de 26\%. Judith Zelikoff et al., da Universidade de Nova York, expuseram ratos a uma concentração de $800 \mu \mathrm{g} / \mathrm{m}^{3}$ de fumaça proveniente da queima de madeira de carvalho por uma hora. Em seguida, os mesmos ratos foram expostos ao Staphylococcus aureus por instilação intratraqueal. Um grupo controle, não exposto à fumaça também recebeu o mesmo tratamento. A bactéria mostrouse mais virulenta nos ratos expostos à fumaça e os autores sugeriram que a fumaça suprime a atividade dos macrófagos ${ }^{(81)}$.

\section{QUEIMA DE BIOMASSA EM AMBIENTES ABERTOS E AGRAVOS À SAÚDE}

Se os estudos avaliando poluição em ambientes fechados por queima de biomassa são pródigos em demonstrar efeitos adversos, o mesmo não acontece em relação à poluição em ambientes abertos. A própria OMS reconhece que a intensidade e a gravidade dependem de uma série de fatores, como: características dos poluentes, características da população exposta, exposição individual, suscetibilidade do individuo exposto e fatores de confusão ${ }^{(4)}$. A fumaça decorrente da queima de biomassa em ambientes abertos produz efeitos adversos indiretos sobre a saúde, como a redução da fotossíntese, o que provoca diminuição das culturas agrícolas, ou o bloqueio dos raios ultravioletas A e B, o que provoca um aumento de microorganismos patogênicos no ar e na água, 
TABELA 3

Estudos que avaliam a exposição da população à combustão de biomassa em ambientes internos realizados em paises desenvolvidos

\begin{tabular}{|c|c|c|c|c|}
\hline população & $\begin{array}{l}\text { Desenho } \\
\text { do estudo }\end{array}$ & desfecho & resultados & referência \\
\hline Crianças & Transversal & Sintomas & $\begin{array}{l}\text { Aumento da tosse, sibilos, e sintomas } \\
\text { alérgicos em residências com queima } \\
\text { de madeira. }\end{array}$ & Honichy-RE, $1985^{(66)}$ \\
\hline Crianças & Transversal & $\begin{array}{l}\text { Sintomas, } \\
\text { doenças } \\
\text { respiratórias }\end{array}$ & $\begin{array}{l}\text { Aumento da incidência de doenças } \\
\text { respiratórias em residências com } \\
\text { queima de madeira; não houve efeitos } \\
\text { em sintomas. }\end{array}$ & Dockery et al. $1987^{(67)}$ \\
\hline Crianças & Longitudinal & Sintomas & $\begin{array}{l}\text { Aumento na freqüência dos sibilos e } \\
\text { da tosse com aumento de horas no uso } \\
\text { de forno a lenha }\end{array}$ & Butterfield et al, 1989 \\
\hline $\begin{array}{l}\text { Crianças }<2 \\
\text { anos }\end{array}$ & Longitudinal & $\begin{array}{l}\text { Patologia } \\
\text { respiratór } \\
\text { ia }\end{array}$ & $\begin{array}{l}\text { Aumento do risco de infecção } \\
\text { respiratória baixa com queima } \\
\text { de madeira }\end{array}$ & Morris et al., $1990^{(69)}$ \\
\hline Criança & Transversal & $\begin{array}{l}\text { Sintomas, } \\
\text { doenças } \\
\text { respiratór ias, } \\
\text { função } \\
\text { pulmonar }\end{array}$ & $\begin{array}{l}\text { Não houve aumento de sintomas ou } \\
\text { patologias e não houve } \\
\text { decréscimo da função } \\
\text { pulmonar com queima de madeira em } \\
\text { residência }\end{array}$ & Vedal, $1993^{(70)}$ \\
\hline Criança & $\begin{array}{l}\text { Caso } \\
\text { controle }\end{array}$ & $\begin{array}{l}\text { Hospitalização } \\
\text { por patologia } \\
\text { respiratória }\end{array}$ & $\begin{array}{l}\text { Aumento de hospitalizações } \\
\text { relacionadas à queima de madeira em } \\
\text { residência; resultados, quando } \\
\text { comparados ao grupo } \\
\text { controle, mostraram aumento } \\
\text { de tosse e dispnéia, nos dias } \\
\text { com queima de madeira }\end{array}$ & Vedal, $1993^{(70)}$ \\
\hline $\begin{array}{l}\text { Adultos } \\
\text { asmáticos }\end{array}$ & Longitudinal & Sintomas & $\begin{array}{l}\text { Aumento de tosse e dispnéia } \\
\text { relacionadas a queima de madeira em } \\
\text { residência }\end{array}$ & Ostro et al., 1994 (71) \\
\hline $\begin{array}{l}\text { Crianças } \\
<2 \text { anos }\end{array}$ & $\begin{array}{l}\text { Caso } \\
\text { controle }\end{array}$ & $\begin{array}{l}\text { Doença } \\
\text { respiratória }\end{array}$ & $\begin{array}{l}\text { Aumento de doença respiratória } \\
\text { aguda com queima de madeira em } \\
\text { residências com } \mathrm{PM}_{10}>65 \mathrm{~g} / \mathrm{m}^{3}\end{array}$ & Robin et al., $1996^{(72)}$ \\
\hline
\end{tabular}

além do aumento de larvas de mosquitos transmissores de doenças ${ }^{(82-84)}$.

Em 1997, em decorrência do fenômeno El Niño, os estados de Kalimatan (Bornéu) e Sumatra (Indonésia) foram afetados por incontroláveis incêndios florestais, que tiveram duração de aproximadamente dois meses (entre julho e setembro) e resultaram em um episódio de grande poluição do ar, com impactos sobre a população em uma ampla região do sudoeste asiático, como na Indonésia, Malásia, Cingapura, sul da Tailândia, Brunei, e sul das Filipinas. Aproximadamente 1.500 focos de incêndio provocaram a queima de 550 mil hectares de florestas e uma área total de queima de biomassa de 4,5 milhões de hectares.
A névoa decorrente desse processo cobriu 3 milhões de hectares, afetando uma população de 300 milhões de pessoas e provocando um gasto com saúde de 4,5 bilhões de dólares. Isso despertou a atenção das autoridades sanitárias de todo o mundo ${ }^{(85)}$.

Segundo a Secretaria Central de Estatística da Indonésia, entre setembro e outubro de 1997, em oito províncias do pais, num total de aproximadamente 12,5 milhões de habitantes, houve aumentos nos atendimentos por asma brônquica, bronquite crônica e infecção respiratória aguda, atingindo 1.802 .340 casos. As patologias respiratórias motivaram 36.462 visitas ao pronto socorro, 15.822 internações, e 2.446.352 dias de 
TABELA 4

Estudos que avaliaram a exposição da população à combustão de biomassa em ambientes abertos realizados em países desenvolvidos, nos quais a biomassa não é a única fonte de emissão de poluentes.

\begin{tabular}{|c|c|c|c|c|}
\hline População & Desenho do estudo & Desfecho avaliado & resultados & referencia \\
\hline Crianças & Longitudinal & Função pulmonar & $\begin{array}{l}\text { Decréscimo da função pulmonar } \\
\text { durante e após a estação de } \\
\text { queima de madeira em } \\
\text { comunidade exposta, mas não em } \\
\text { comunidade controle }\end{array}$ & Heuman et al.; 1990 (73) \\
\hline Crianças & Longitudinal & Função pulmonar & $\begin{array}{l}\text { Decréscimo da função pulmonar no } \\
\text { inverno em comunidade exposta, } \\
\text { mas não na comunidade controle }\end{array}$ & Johnson et al., 1990 (74) \\
\hline Crianças & Longitudinal & Espirometria & $\begin{array}{l}\text { Decréscimo da função pulmonar em } \\
\text { portadores de asma brônquica } \\
\text { relacionado a partículas finas }\end{array}$ & Koenig et al., 1993(75) \\
\hline $\begin{array}{l}\text { Todas as } \\
\text { idades }\end{array}$ & Longitudinal & $\begin{array}{l}\text { Visitas à } \\
\text { emergência }\end{array}$ & $\begin{array}{l}\text { Aumento de atendimentos de } \\
\text { pacientes com crise asmática } \\
\text { relacionado com } \mathrm{PM}_{2,5} \text { em áreas } \\
\text { onde a fumaça da madeira contribui } \\
\text { com } 80 \% \text { do total de partículas finas }\end{array}$ & Schwartz et al., 1993 (76) \\
\hline $\begin{array}{l}\text { Todas as } \\
\text { idades }\end{array}$ & Longitudinal & mortalidade & $\begin{array}{l}\text { Aumento da mortalidade diária } \\
\text { relacionada ao } \mathrm{PM}_{10} \text { em áreas } \\
\text { onde a fumaça da queima de } \\
\text { madeira contribui com } 45 \% \text { do } \\
\mathrm{PM}_{10} \text { no inverno }\end{array}$ & Farley, 1990 (78) \\
\hline
\end{tabular}

trabalho perdidos. Em várias províncias, o Total de Partículas em Suspensão (TSP) excedeu o limite de $260 \mu / \mathrm{m}^{3}$, considerado como aceitável, entre três e quinze vezes. Encontrou-se grande concentração de material particulado com diâmetro que variava entre $0,5 \mu \mathrm{m}$ e $5 \mu \mathrm{m}$ em áreas próximas às regiões mais afetadas pelo incêndio ${ }^{(86)}$.

$\mathrm{Na}$ Malásia houve aumento de crises agudas de asma em crianças e a função pulmonar em escolares decresceu durante o período agudo ${ }^{(87)}$.

O Ministério da Saúde de Cingapura monitorou a qualidade do ar em quinze estações durante o episódio da névoa em 1997. 0 Pollutant Standard Index (PSI) ficou acima de 100 por doze dias com pico de 138. A relação entre o PSI e o material particulado com diâmetro aerodinâmico menor que $10 \mu \mathrm{m}\left(\mathrm{PM}_{10}\right)$ é a seguinte: 100 de PSI corresponde aproximadamente a $150 \mu \mathrm{g} / \mathrm{m}^{3}$ de $\mathrm{PM}_{10}{ }^{\left({ }^{88)}\right.}$. Foram encontradas 94\% de partículas com diâmetros inferiores a $2,5 \mu \mathrm{g} / \mathrm{m}^{3}$ na névoa. Na última semana de setembro, quando os níveis de material particulado atingiram o pico, a vigilância sanitária de Cingapura relatou um aumento de 30\% em atendimentos ambulatoriais relacionados a patologias respiratórias. Um aumento nos níveis do $\mathrm{PM}_{10}$ de $50 \mu \mathrm{g} / \mathrm{m}^{3}$ para $150 \mu \mathrm{g} / \mathrm{m}^{3}$ foi significativamente associado a um aumento de 13\%, 19\% e 26\% em infecção respiratória aguda, asma e rinite respectivamente ${ }^{(89)}$.

Na região central de Kalimantan, Bornéu, uma das áreas mais afetadas pela névoa, por um período de seis meses a partir de julho de 1997, o número de pacientes hospitalizados com pneumonia em setembro foi 33 vezes maior do que nos doze meses prévios. Relatórios do Hospital Distrital de Jambi (Sumatra) mostram que no mês de setembro houve aumento de internações por bronquite, laringite aguda e bronquiectasias, de 1,6, 8,0 e 3,9 vezes, respectivamente, em relação à média histórica.

Em Jambi (Sumatra), uma amostra de 539 indivíduos respondeu a um questionário com 0 objetivo de avaliar os efeitos da poluição do ar sobre a população. Relataram algum tipo de 
sintoma 532 indivíduos (99,7\%), e 491 (91,1\%) referiram sintomas respiratórios. Os sintomas relatados foram considerados de média intensidade, mas a maioria dos entrevistados relatou mais de um sintoma e 85,9\% relataram mais de 10 sintomas. Os entrevistados com idade acima de 60 anos referiram sintomas graves e relataram piora significativa na qualidade de vida $^{(90)}$.

0 sul da Tailândia foi coberto pela fumaça oriunda do incêndio durante dois meses, entre setembro e outubro de 1997. Houve um substancial aumento da morbidade respiratória, o que provocou aumento das internações hospitalares e de consultas ambulatoriais. A diferença percentual entre as internações hospitalares e consultas ambulatoriais da região sul (afetada) e da região norte (controle) foi de 26:18 para todas as consultas por doenças respiratórias, 33:18 para todas as admissões por doenças respiratórias, 36:18 para admissão por pneumonia, 40:28 para admissão por DPOC e 12:9 para admissão por asma. Os relatórios mensais mostraram que a morbidade por doenças respiratórias aumentou durante o episódio da névoa em aproximadamente $45 \mathrm{mil}$ visitas ambulatoriais e 1.500 admissões hospitalares no sul da Tailândia. Modelos de análise de regressão demonstraram uma significativa associação entre a admissão hospitalar por doença respiratória e níveis mensais de $\mathrm{PM}_{10}$. Uma elevação de $10 \mu \mathrm{g} /$ $\mathrm{m}^{3}$ na média mensal de $\mathrm{PM}_{10}$ significou aumentos no número de admissões hospitalares da ordem de 85\%, 28\%, 13\% e 13\% para doença respiratória em geral, pneumonia, DPOC e asma brônquica, respectivamente ${ }^{(91)}$.

Tan et al. ${ }^{(92)}$ avaliaram a contagem de leucócitos em 30 voluntários (militares) sem doença prévia, utilizando amostras de sangue periférico, e compararam o período da névoa (29/09 a 27/10/ 1997) com o período após a névoa $(21 / 11$ a $5 / 12 /$ 1997) em Cingapura. 0 resultado mostrou que durante o período de maior poluição do ar houve um aumento relevante no número de leucócitos devido a um aumento no percentual de polimorfonucleares. Este efeito foi mais agudo em relação ao $\mathrm{PM}_{10}$ (efeitos associados às concentrações do poluente no dia do evento e um dia antes) do que em relação ao dióxido de enxofre (efeito associado à concentração do poluente três a quatro dias antes do evento). Os autores sugerem que a poluição atmosférica causada pela queima de biomassa está associada a um aumento na contagem de glóbulos brancos no sangue periférico, em virtude de um aumento na liberação dos precursores dos polimorfonucleares pela medula óssea, e que essa resposta pode contribuir para a patogênese da morbidade cárdio-respiratória associada a episódios agudos de poluição do ar. Eeden et al. ${ }^{(93)}$, utilizando o mesmo grupo de indivíduos, demonstraram que houve aumento das citocinas circulantes, o que confirmou a hipótese levantada pelo estudo de Tan et al..

Antes do episódio do sudoeste asiático, eram poucos e não devidamente valorizados os estudos que avaliavam a exposição da população à queima de biomassa a céu aberto. Relatos de efeitos adversos provocados por eventos de queima descontrolada de vegetação remontam à década de 1960, quando Greemburg et al. ${ }^{(94)}$ relataram um episódio ocorrido em Nova York nove anos antes, em 3/11/1952, quando a fumaça proveniente da queima de uma floresta "apagou o sol". Nesse dia houve um aumento de mortalidade de 20\% em relação à média diária observada no mês.

Em 1987, um incêndio de grandes proporções na Califórnia (EUA) elevou os níveis de TSP e PM ${ }_{10}$ a valores de até 1000 e $237 \mu \mathrm{g} / \mathrm{m}_{3}$, respectivamente. Esse fato causou um aumento na procura de atendimentos de pronto-socorro por asma, DPOC, laringite, sinusite e outras infecções respiratórias da ordem de 40\%, 30\%, 60\%, 30\%, e 50\%, respectivamente ${ }^{(95)}$.

Individuos portadores de patologias respiratórias crônicas mostram-se mais susceptiveis aos efeitos da poluição gerada pela queima de vegetação. Durante incêndios florestais ocorridos em 1994, em Cingapura, foi registrado um aumento de $20 \%$ na procura de atendimentos em pronto-socorros por crianças asmáticas em comparação às médias anuais ${ }^{(96)}$. Em relação aos adultos, a fumaça proveniente da queima de palha e residuos agrícolas produziu em individuos portadores de obstrução de vias aéreas, de intensidade moderada a grave, exacerbações de sintomas, como dispnéia, desconforto respiratório, tosse e sibilos ${ }^{(97)}$.

Existem evidências de que não apenas os indivíduos com patologias prévias são afetados pelos poluentes do ar. Os bombeiros que atuam em incêndios florestais compreendem um grupo 
ocupacional de indivíduos com alta exposição à queima de biomassa. Estudos realizados com esses bombeiros indicam uma associação entre exposição ao material particulado e efeitos agudos sobre o sistema respiratório, além de irritação nos olhos, nariz e garganta, e diminuição de parâmetros da função pulmonar (CVF, VEF ${ }_{1}$, e fluxo expiratório forçado a 25\% - 75\% da CVC $\left.\mathrm{FEF}_{25-75}\right)^{(98-101)}$. Estudos prospectivos mostraram que esses efeitos podem ser reversíveis após o individuo se afastar da exposição à fumaça.

Devemos considerar, entretanto, que a polícia florestal é uma parcela da população hígida, sem doenças prévia, e, em princípio, bem mais saudável que a média da população em geral. Portanto, é razoável supor que efeitos similares podem ser observados na população geral em exposições semelhantes ou menores.

\section{Queima da palha de cana-de-acúcar e agravos à saúde no Brasil}

Todos os estudos relacionados à queima de vegetação a céu aberto dizem respeito a episódios fortuitos. Existe, porém, uma região do planeta em que a queima da biomassa se faz de maneira programada. Na década de 1970, durante a crise do petróleo, o governo brasileiro implementou um programa chamado Proálcool com o objetivo de produzir um combustível alternativo, renovável, e não poluente: o etanol, derivado da cana-deaçúcar. Esse programa culminou com uma grande produção de veículos movidos a álcool a partir da década de 80, e com um grande incremento da cultura da cana-de-açúcar. Em 1996, somente cinco estados da federação não produziam canade-açúcar (Acre, Amapá, Pará, Rio Branco e Rondônia), sendo São Paulo o maior produtor, com aproximadamente $65 \%$ do total da produção nacional. Com a crescente utilização do álcool como combustível em veículos automotores houve uma melhora na qualidade do ar nos grandes centros urbanos. Existe, porém, um contraponto: a cana-de-açúcar é uma cultura agrícola singular, uma vez que, por razões de produtividade e de segurança, sua colheita é realizada após a queima dos canaviais, o que gera uma grande quantidade de elemento particulado negro denominado "fuligem da cana". Esse material particulado modifica as características do ambiente nas regiões onde a cana-de-açúcar é cultivada, colhida e industrializada. Essas regiões são laboratórios naturais onde a população fica exposta, por aproximadamente seis meses ao ano, aos poluentes provenientes da queima de biomassa.

O Laboratório de Poluição Atmosférica Experimental (LPAE) do Departamento de Patologia da Faculdade de Medicina da Universidade de São Paulo foi pioneiro em nosso país na avaliação dos efeitos tóxicos dos poluentes emitidos pela queima de combustíveis fósseis nos grandes centros urbanos e seus efeitos sobre os seres humanos ${ }^{(102-104)}$. Foi também o pioneiro na avaliação dos efeitos tóxicos da combustão do álcool, da mistura álcool/gasolina e na sua posterior comparação com os efeitos tóxicos da combustão da gasolina e da mistura chumbo/ gasolina. ${ }^{(105,106)}$.

A potencial gravidade da situação foi eloqüente o suficiente para que o LPAE enveredasse por um novo caminho de pesquisa: estimar os efeitos da poluição do ar causada pela queima de biomassa.

Foram definidas duas regiões do Estado de São Paulo para sediar estes estudos: Araraquara e Piracicaba , que estão entre os maiores produtores de cana-de-açúcar do planeta. Relatórios da Companhia de Tecnologia de Saneamento Ambiental (CETESB) $^{(107,108)}$, emitidos em 1986 e em 1999, sobre a qualidade do ar em Araraquara, mostravam um importante aumento da poeira total em suspensão e do $\mathrm{PM}_{10}$ no período da safra da cana-de-açúcar, em comparação com o período de não safra.

Do ponto de vista médico, o interesse pelo problema reside no fato de que muitos pacientes com doenças crônicas do aparelho respiratório, principalmente bronquite crônica, enfisema, e asma, referem agravamento dos seus sintomas no período do ano que coincide com a queimada da cana. Mas não é só. Indivíduos hígidos, na mesma época do ano, referem, com freqüência, irritação em vias aéreas superiores com ardor no nariz e na garganta. A presença na atmosfera de resíduos grosseiros resultantes da combustão da cana-deaçúcar aparece, para a população em geral, como a evidência de que os sintomas respiratórios dependem ou são agravados pela poluição ambiental gerada pelas queimadas.

Entretanto, o problema não é tão simples quanto aparenta. Não se pode, por exemplo, descartar a possibilidade de que alterações climáticas sejam as responsáveis pelo agravamento 
dos sintomas respiratórios em uma parcela de indivíduos da população.

Franco(109), em 1992, formulou algumas considerações a respeito da relação entre a queima da cana-de-açúcar e agravos à saúde:

1. durante a época das queimadas dos canaviais há uma piora na qualidade do ar na região;

2. a queimada dos canaviais não é o único fator de agravamento da qualidade do ar, mas em conseqüência da extensão da área plantada e da duração das queimadas, final de abril a início de novembro, as descargas de gases e de outros poluentes na atmosfera da região ganham um significado importante e não podem ser menosprezadas;

3. a população de risco, que tem sua qualidade de vida e de saúde agravada em condições atmosféricas adversas, é bastante significativa;

4. a maioria das pessoas que compõem a população de risco demanda um número muito maior de consultas, atendimentos ambulatoriais, medicação, e internações. 1sso onera não só os serviços médicos, mas a economia das famílias.

Considerando a escassez de trabalhos correlacionando os efeitos da queimada da canade-açúcar e a dimensão da população de risco e dos ônus médico, social e econômico dessa condição, o nosso grupo de pesquisa decidiu abordar a questão.

Um estudo epidemiológico de série temporal, com o objetivo de avaliar a associação entre o material particulado coletado durante a queima de plantações de cana-de-açúcar e um indicador de morbidade respiratória em Araraquara foi desenvolvido entre 26 de maio e 31 de agosto de 1995. O número diário de pacientes que necessitaram inalações em um dos principais hospitais da cidade foi quantificado, e utilizado para estimar a morbidade respiratória. Encontrouse uma associação positiva significante e dosedependente entre o número de terapias inalatórias e o peso do sedimento, utilizado como medida do material particulado gerado pela queima da canade-açúcar. Um aumento de $10 \mathrm{mg}$ no peso do sedimento esteve associado a um risco relativo de terapêutica inalatória de 1,09 (1C 95\%: 1,01-1,18). Nos dias mais poluídos, o risco relativo de terapêutica inalatória foi de 1,20 (1,03-1,39). Esses resultados indicam que a queima das plantações da cana-de-açúcar pode causar efeitos deletérios à saúde da população exposta(110,111).

0 LPAE prosseguiu os estudos analisando a influência da poluição atmosférica proveniente da queima da palha da cana-de-açúcar sobre as doenças respiratórias na cidade de Piracicaba. Nesta cidade, havia condições propícias para 0 desenvolvimento de um trabalho visando avaliar as contribuições tanto da poluição gerada pela queima de biomassa como aquela derivada da queima de combustiveis fósseis sobre a saúde humana. Lara ${ }^{(112)}$ coletou, entre abril de 1997 e março de 1998, material particulado, separandoo em frações fina e grossa. Ele foi então analisado e quantificado para black carbon (BC), Al, Si, P, S, $\mathrm{Cl}, \mathrm{K}, \mathrm{Ca}, \mathrm{Ti}, \mathrm{V}, \mathrm{Cr}, \mathrm{Mn}, \mathrm{Fe}, \mathrm{Ni}, \mathrm{Cu}, \mathrm{Zn}, \mathrm{Br}, \mathrm{Pb}^{(112)}$. No mesmo período quantificaram-se as internações hospitalares diárias por doenças respiratórias, em crianças e adolescentes (abaixo de 13 anos de idade), e em idosos (maiores de 65 anos de idade) através de dados do Departamento de Informática do Sistema Único de Saúde (DATASUS). A análise dos componentes principais absoluta identificou que a queima de biomassa e a re-suspensão do material erodido do solo (Fator 1) são responsáveis por $80 \%$ do material particulado fino $\left(\mathrm{PM}_{2,5}\right)$. 0 risco relativo de internações hospitalares por doenças respiratórias em crianças e adolescentes foi significativamente associado à variação interquartil do $\mathrm{PM}_{10}, \mathrm{PM}_{2,5}$, $\mathrm{BC}, \mathrm{Al}, \mathrm{Si}, \mathrm{Mn}, \mathrm{K}$, e S. Um aumento de $10,2 \mu \mathrm{g} / \mathrm{m}^{2,5}$ no $\mathrm{PM}_{2,5}$ associa-se a um aumento de $21,4 \%$ (95\% Cl 4,$3 ; 38,5)$ nas internações por doenças respiratórias em crianças e adolescentes. Em idosos, o risco relativo de internações hospitalares por doenças respiratórias está também significativamente associado à variação interquartil do $\mathrm{PM}_{10} \mathrm{BC}$, e K. Quando se compararam os períodos de queima e de não queima da palha da cana-de-açúcar, o efeito foi 3,5 vezes maior no período da queima, o que mostra o impacto desta sobre a saúde da população na cidade de Piracicaba (113).

\section{CONCLUSÕES}

As mudanças físicas e biológicas ocorridas no ambiente devidas à atividade humana resultaram em um enorme impacto sobre a saúde. A extensão 
dessas mudanças, que repercute nos dias de hoje, e ainda compromete o futuro, não está totalmente estabelecida. Por exemplo, emissões passadas de monóxido de carbono e outros gases geradores do efeito estufa, e a depleção da camada de ozônio na estratosfera, ainda são problemas atuais com os quais nos defrontamos. Da mesma forma, a contínua modificação dos sistemas ecológicos que sustentam a vida humana poderá representar no futuro uma ameaça à saúde de forma global. Devido aos efeitos dos gases estufa, a temperatura da superfície terrestre aumentou aproximadamente $1,2^{\circ} \mathrm{C}$ desde 1850 , sendo $0,5^{\circ} \mathrm{C}$ entre 1978 e os dias de hoje, o que leva a um contínuo aquecimento da superfície dos oceanos, o que provoca mudanças de direção nas correntes marinhas profundas, com dramáticas mudanças climáticas regionais, acarretando problemas como escassez de água e alimentos.

Entre as razões do contínuo desenvolvimento da espécie humana encontra-se a proteção à saúde. Porém, ainda há uma lentidão na avaliação e implementação de medidas saneadoras quando se trata da relação ambiente e saúde, muito especialmente quando se trata de queima de biomassa. Segundo a American Lung Association $^{(114)}$, mais de 800 novos estudos científicos que associam os efeitos do material particulado em suspensão no ar, proveniente da queima de combustíveis fósseis, sobre a saúde humana, foram publicados entre 1997 e 2001. Entretanto, a literatura é extremamente parcimoniosa ao avaliar os efeitos sobre a saúde humana da combustão de biomassa, seja em ambientes internos, modalidade de obtenção de energia utilizada por três bilhões de indivíduos no planeta, seja por queima de vegetação a céu aberto, em relação à qual ainda hoje não existem estimativas precisas do número de pessoas expostas aos poluentes liberados. Ainda hoje não se consegue determinar a causa do início do fogo em vegetação em 50\% dos episódios, o que torna a queima de vegetação a céu aberto na Ásia, na América, na África e em outras partes do mundo um fenômeno recorrente. Estimativas mostram que, no ano 2000, 351 milhões de hectares de vegetação do planeta foram afetados pelo fogo. A população atingida pelos produtos gerados pela combustão de biomassa, via de regra, corresponde aos individuos com maior grau de pobreza, e com menor possibilidade de acesso aos serviços de saúde, o que certamente faz piorar a sua já precária qualidade de vida.

Os dados apresentados nesta revisão devem ir além de simplesmente identificar as populações mais afetadas pela queima de biomassa e descrever os complexos mecanismos de impactos sobre a saúde, mas também devem enviar uma mensagem aos pesquisadores, no sentido de expandir o limitado conjunto de conhecimentos e, dessa forma, possibilitar a criação de programas efetivos de intervenção com o objetivo de proporcionar uma melhor qualidade de vida aos individuos expostos.

\section{REFERÊNCIAS}

1. Bascon R, Bromberg PA, Costa DA, Devlin R, Dockery DW, Frampton MW, Lambert W, Samet JM, Speizer FE, Utell M. Health effects of outdoor pollution. Am. J. Respir. Crit. Care Med 1996; 153: 3-50.

2. De Koning HW, Smith KR, Last JM, Biomass fuel combustion and health. Bull. WHO 1985; 63:11-26.

3. WHO Information, VEGETATION FIRES, 2000 Fact Sheet, $\mathrm{n}^{\circ} 254$

4. WHO. Health Guidelines for Vegetation Fire Events, ed. Schwela DH Goldammer JG, Morawska LH, Simpson, 0. Geneva, World Health Organization, 1999.

5. Cochrane ME. O grande incêndio de Roraima. Ciência Hoje 2000; 27:26-43.

6. Crutzen PJ, Andreae MO. Biomass burning in the tropics: Impacts on atmospheric chemistry and biogeochemical cycles. Science 1990; 250:1669-78.

7. Lacaux JP, Loemba-Ndembi J, Lefeivere B. Biogenic emissions and biomass burning influences on the chemistry of the fogwater and stratiform precipitations in the African equatorial Forest. Atmospheric Environment $1992 ; 26: 541-51$

8. Losno R, Bergametti G, Cartier P, et al. Major ions in marine rainwater with attention to sources of alkaline and acidic species. Atmospheric Environment 1991; 25:763-70

9. Ward DE, Susott RA, Kauffmann JB, et al. Smoke and fire characteristics for cerrado and deforestation burns in Brazil- Base-B Experiment. Journal of Geophysical Research 1992; 97:14601-19

10. Botkin D, Keller EA. Environmental Science: Earth as living planet. New York: 1. ed., John Wiley \& Sons, 1995

11.Seaton A, MacNee W, Donaldson K, Godenn D. Particulate air pollution and acute health effects,. Lancet 1995; 345:176-8

12. Peters A, Wichman HE, Tuch T, Heyder J. Respiratory effects are associated with the number of ultrafine particles. Am J Respir Crit Care Med 1997; 155:1376-83

13. Donaldson K, Stone V, Clouter A, MacNee W. Ultrafine Particles. Occup Environ Med 2001; 58:211-6.

14. Shi, MM, Godleski JJ, Paulauskis JD. Regulation of macrophage inflammatory protein-1 mRNA by oxidative stress. J. Biol. Chem 1996; 271: 5878-83 
15. Turn SQ, Jenkins BM, Chow JC, Pritchett LC, Campbell D, Cahill T, Whalen SA. Elemental characterization of particulate matter emitted from biomass burning: Wind tunnel derived source profiles for herbaceous and wood fuels. Journal of Geopysical Research 1997; 102: 268399

16. Bruce N, Perez-Padilla R, Albalak R. Indoor air pollution in developing countries: a major environmental and public health challenge. Bull. WHO 2000; 78: 1078-92.

17. Padmavati S, Pathak, SN. Chronic cor pulmonale in Delhi. Circulation 1959; 20:343-52.

18. Padmavati S, Joshi, B. Incidence and etiolgy of chronic cor pulmonale in Delhi: a necropsy study. Dis Chest 1964; 46, 457-63

19. Behera D, Jindal SK, Malhota HS. Ventilatory function in nonsmoking rural lndian women using different cooking fuels. Respiration 1994; 61:89-92.

20. Master KM. Air pollution in New Guinea. Cause of chronic pulmonary disease among stone-age natives in the highlands. JAMA 1974; 228:1635.

21. Anderson HR. Respiratory abnormalities and ventilatory capacity in a Papua New Guinea lsland community. Am Rev Respir Dis. 1976; 114:537-48

22. Anderson HR. Chronic lung disease in the Papua New Guinea highlands. Thorax 1979; 34:647-53.

23. Pandey MR. Prevalence of chronic bronchitis in a rural community of the Hill Region of Nepal. Thorax 1984; 39:331-6.

24. Pandey, MR. Domestic smoke pollution and chronic bronchitis in a rural community of the Hill Region of Nepal. Thorax 1984; 39:337-9.

25. Norboo T, Yahya NB, Heady JA, Ball KP. Domestic pollution and respiratory illness in a Himalayan village. Int. J. Epidemiol 1991; 20:749-57.

26. Qureshi K. Domestic smoke pollution and prevalence of chronic bronchitis/asthma in a rural area of Kashmir. Indian J Chest Dis Allied Sci 1994; 36: 61-72

27. Dossing M. Risk factors for chronic obstructive lung disease in Saudi Arabia . Respir. Med 1994; 88:519-22

28. Dennis RJ, Maldonado D, Norman S, Baena E, Martinez G. Woodsmoke exposure and risk for obstructive airways disease among women. Chest 1996; 109:115-9.

29. Perez-Padilla R, Regalado J, Vedal S, Chapela R, Samspre $\mathrm{R}$, Selman M. Exposure to biomass smoke and chronic airway disease in Mexican women. A case control study. Am. J. Respir. Crit. Care Med 1996; 154:701-6.

30. Regalado J, Perez-Padilla R, Sansores R, Vedal S, Brauer $M$, Pare P. The effect of biomass burning on respiratory symptoms and lung function in rural women. Am J Resp Crit Car Med. 153 :A171

31. Albalak R, Frisancho AR, Keeler GJ. Domestic biomass fue combustion and chronic bronchitis in two rural Bolivian villages. Thorax 1999; 54:1004-8.

32. Menezes AM, Victora CG, Rigatto M. Prevalence and risk factors for chronic bronchitis in Pelotas, RS, Brazil: a population-base study. Thorax 1994; 49:1217-21

33. Ellegard, A. Cooking fuel smoke and respiratory symptoms among women in low-income areas of Maputo. Environ. Health Perspect 1996; 104:980-5.

34. Narboo T, Angehuk p. Yahya m. Silicosis in a Himalaya Village population: Role of environmental dust. Thorax 1991; 46: 341-3.
35. Saiyed HN, Sharma YK, Sadhu HG, Norboo T, Patel PD, Patel TS, Venkaiah K, Kashyap SK.Non-occupational pneumoconiosis at high altitude villages in central Ladarkh.Br J lnd Med 1991; 48:825-9.

36. Grobbelar JP, Bateman ED.Hut lung: a domestically acquire pneumoconiosis of mixed etiology in rural women. Thorax; 1991; 46:334-40.

37. Sandoval JJ, Salas MI, Martinez-Guerra A, Portales A, Palomar M, Villegas, Barrios R. Pulmonary arterial hypertension and cor pulmonale associated with domestic wood smoke inhalation. Chest 1993; 103: $12-20$

38. Cerquiero MC, Murtagh P, Halc M, Weissenbacher M. Epidemiologic risk factors for children with acute lower respiratory tract infection in Buenos Aires, Argentina: a matched case control study. Rev. Infect. Dis. 1990: 12, suppl 8: S1021-8.

39. Collings DA, Sithole SD, Martin KS. Indoor air pollution in developing countries and acute respiratory infection in children. Tropical Doctor 1990; 20: 151-5.

40. Mtango FD, Neuvians D, Broome CV, Hightowwer AW, Pio A. Risk factors for deaths in children under 5 years old in Bagamoyo district, Tanzania. Trop. Med. Parasitol 1992; 43:229-33.

41. Johnson AW, Aderele Wl. The association of household pollutants and socio-economic risk factors with the shortterm outcome of acute lower respiratory infections in hospitalized pre- school Nigerian children. Ann. Trop. Paediatr 1992 12:421-32.

42. Shah N, Ramankutty V, Premila PG \& Sathy N. Risk factors for severe pneumonia in children in south Kerala: a hospital-based case-control study. J Trop Pediatr 1994; 40:201-6.

43. Victora CG, Fuchs SC, Flores JA, Fonseca W, lrkwwood B. Risk factors for pneumonia among children in a Brazilian metropolitan area. Pediatrics 1994; 93:977-85.

44. O'Dempsey T, McArdle TF, Morris J, Lloyd-Evans N, Bldehi, Laurence BE, et al. A study for pneumococcal disease among children in a rural area of West Africa. Int J Epidemiol 1996; 25:885-93.

45. Wesley AG, Loening WE. Assessment and 2-year followup of some factors associated with severity of respiratory infections in early childhood. S. Afr. Med. J

46. Lopez-Bravo IM, Sepulveda H, Valdes I. Acute respiratory illness in the first 18 months of life. Pan. Am. J. Public Health $1997 ; 1: 9-17$.

47. Kossove D. Smoke-filled rooms and lower respiratory disease in infants. South Afr. Med. J 1982; 61:622-4.

48. Pandey MR, Boleij JS, Smith KR, Wafula EM. Indoor air pollution in developing countries and acute respiratory infection in children. Lancet 1989; 1:427-9.

49. Campbell H, Armstrong JR, Byass P. Indoor air pollution in developing countries and acute respiratory infection in children. Lancet $1989 ; 1: 1012$.

50. Armstrong JR, Campbell H. Indoor air pollution exposure and lower respiratory infections in young Gambian children. Int. J. Epidemiol 1991; 20:424-9.

51. De Francisco A, Morris J, Hall AJ, ArmstrongSchellenberg JR, Greenwood BM. Risk factors for mortality from acute lower respiratory tract infections in young Gambian children. Int. J. Epidemiol 1993; 22:1174-82. 
52. Ezatti M, Kammen D.Quntifying the effects of exposure to indoor air pollution from biomass combustion on acute respiratory infections in developing countries. Environmental Health Perspectives 2001; 109:481-8.

53. Ezzati M, Kammen DM. Indoor air pollution from biomass combustion and acute respiratory infections in Kenyaan exposure response study. Lancet 2001 ; 358:619-24

54. Smith KR, Samet JM, Romieu I, Bruce N. Indoor air pollution in developing coutries and aculte lower respiratory infections in children. Thorax 2000: 55: 518-32

55. Mavalankar DV, Trivedi CR, Gray RH. Levels and risk factors for perinatal mortality in Ahmedabad, India. WHO Bulletin 1991; 69: 435-42.

56. Boy E, Bruce N, Delgado H. Birth weight and exposure to kitchen wood smoke during pregnancy. Environ Health Perspective 2002; 110: 109-14

57. Mohammed N, Ng'Ang'A L, Odhiambo J, Nyamwaya J, Menzies R. Home environment and asthma in Kenyan school children: a case-control study. Thorax 1995; 50:74-8

58. Melson T, Brinch J, Hessen J0, Schei M etal. Asthma and indoor environment in Nepal. Thorax 2001; 56:477-81.

59. Shei MA, Hessen JO, McCraken J, Lopez V, Bruce NG, Smith KR. Asthma and indoor air pollution among indigenous children in Guatemala. Proc Indoor air 2002, Monterey, CA ( $1^{\text {st }}-7^{\text {th }}$ July 2002$)$

60. Azizi BH, Zulfkfli HI, Kasim S. Indoor air pollution and asthma in hospitalized children in a tropical environment. J. Asthma 1995; 32:413-8.

61. Gupta Bn, Mathur N, Mahendra P, Srivastava A, Swaroop V, Agnihotri M. A study of the household environmental risk factors pertaining to respiratory disease. Energy Environ. Rev 1997; 13:61-7.

62. Mishra VK, Retheford RD, Smith KR. Biomass cooking fuels and prevalence of tuberculosis in India. Int. J. Infect. Dis 1999; 3: 119-29.

63. Perez-Padilla R, Perez-Guzman C, Baez-Saldana R, TorresCruz A. Cooking with biomass stoves and tuberculosis: a case control study. Int. J. Tuberc. Lung Dis 2001; 5:441-7.

64. Ellegard A. Tears while cooking: an indicator of indoor air pollution and related health effects in developing countries. Environ. Res 1997; 45:12-22.

65. Mishra VK, Retheford RD, Smith KR. Biomass cooking fuels and prevalence of blindness in India. J. Environ. Med 1999; 1:189-99.

66. Honick RE, Osborne JS 3rd, Akpom CA. Symptom of respiratory lllness in young children and the use of woodburning stoves for indoor heating. Pediatrics 1985; 75:587-93.

67. Dockery D, Spengler J, et al. Association of health status with indicators of indoor air pollution from and epidemiologic study in six U.S. cities. International Conference on Indoor Air Quality and Climate, Berlin, Institute for Water Soil and Air Hygiene. 1987

68. Butterfield P, LaCava G, Edumunston E, Penner J. Woodstoves and indoor air: the effects on preschoolers' upper respiratory systems. J. Environ Health 1989; 52: 172-3.

69. Morris K, Morgenlander M, Coulehan Jl, Gahagen S, Arena VC. Wood-burning stoves and lower respiratory tract infection in American Indian children. Am. J. Dis. Child 1990; 144:105-8.
70. Vedal S. Health effects of wood smoke. report to the provincial health office of British Columbia. Vancouver, BC, The University of British Columbia. 1993

71. Ostro BD, Lipsett MJ, Mann JK, Wiener MB, Selner J. Indoor air pollution and asthma: Results from a panel study. Am J Respir Crit Care Medicine. 1994 149:14006

72. Robin L, Lees PSJ, Winget M, Steinhoff M, Moulton, LH, Santosham M, Correa A. Wood-burning stoves and lower respiratory illness in Navajo children. Pediatric Infectious Disease Journal 1993; 15:859-65

73. Heuman M, Foster LR, Johnson L, Kelly L. Wood smoke air pollution and changes in pulmonary function among elementary school children. $84^{\text {th }}$ Annual Meeting of the Air and Waste Management Association, Vancouver, BC, Air and Waste Management Association. 1991.

74. Johnson K, Gideon R, Loftsgaarden DO. Montana air pollution study: children's health effects. J Official Stat. 1990; 5:391-408.

75. Koenig J, Larson TV, Hanley QS, Rebolledo V, Dumler K, Checkoway H, Wang SZ, Lin D, Pierson WE. Pulmonary function changes in children associated with fine particulate matter. Environ Res 1993; 63:26-38.

76. Schwartz J, Koenig J, Slater D. Particulate air pollution and hospital emergency room visits for asthma in Seattle. Am Rev Respir Dis 1993; 147:826-31.

77. Lipsett M, Hurley S, Ostro B. Air Pollution and Emergency Room Visits for Asthma in Santa Clara County, California. Environmental Health Perspectives 1997; 105:216-22.

78. Fairley D. The Relationship of Daily Mortality to Suspended Particulates in Santa Clara County, 1980-1986. Environ Health Perspect 1990; 89: 159-68.

79. Fick RB, Paul ES, Merril WW, Reynolds HY, Loke JSO. Alteration in the antibacterial properties of rabbit pulmonary macrophages exposed to wood smoke. Am. Rev. Respir. Dis 1984; 129:76-81.

80. Houtmeyers E, Gosselink R, Gayan-Ramirez G, Decramer M. Regulation of mucociliary clearance in health and disease. Eur. Respir. J. 1999; 13:1177-88.

81. Brauer M. Health impacts of biomass air ln: HEALTH GUIDELINES FOR VEGETATION FIRE EVENTS, Lima, Peru, 1998. Geneva, WHO, 1999; 186-220. (Background papers).

82. Mims FM 3rd. Significant reduction of UVB caused by smoke from biomass burning in Brazil. Photochem Photobiol 1996; 64: 814-6

83. Mims FM $3^{\text {rd }}$, Holben BN, Eck TF, Montgomery BC, Grant WB. Smoky skies, mosquitoes, and disease. Science 1997; 276: 1773-6 (in letters)

84. Mims FM $3^{\text {rd }}$. Health effects of tropical smoke. Nature 1997; 390: 222-3

85. Heil A, Goldameer JG. Smoke -haze pollution: A review of the 1997 episode in South East Asia. Journal of Regional Environmental Change 2001

86. Dawud Y. Smoke Episodes and Assessment of Health impacts Related to Haze from Forest Fires: Indonesian Experience. In: HEALTH GUIDELINES FOR VEGETATION FIRE EVENTS, Lima, Peru, 1998. Geneva, WHO, 1999; 313-33. (Background papers).

87. WHO Bi-Regional Workshop on Health Impacts of HazeRelated Air Pollution, Kuala Lumpur, Malaysia, 1998. Geneva, WHO, 1998, p.1-8 (Annex H). 
88. U.S. ENVIRONMENTAL PROTECTION AGENCY. Measuring Air Quality: The Pollutant Standards Index. Office of Air Quality Planning and Standards, Research Triangle Park, NC, EPA 451/K-94-001, 1994.

89. Brauer M, Hisham-Hashim J. Indonesia Fires: Crisis and Reaction. Environ. Sci. Technol 1998; 32:404-7.

90. Kunii 0 . Basic facts-determining downwind exposures and their associated health effects in practice: a case study in the 1997 forest fires in Indonesia. In: HEALTH GUIDELINES FOR VEGETATION FIRE EVENTS, Lima, Peru, 1998, Geneva, WHO, 1999; 295-312. (Background papers).

91. Phonboon K, Paisarn-Uchapong 0, Kanatharana P, Agsorn S. Smoke episodes emissions characterization and assessment of health risks related downwind air qualitycase study, Thailand. In: HEALTH GUIDELINES FOR VEGETATION FIRE EVENTS, Lima, Peru, 6-9. 1998. Geneva, WHO, 1999; 334-58. (Background papers).

92. Tan CW, Qiu D, Liam BL, NG, TP, Lee SL, Van Eeden, S.F.; D'Yachkova, Y.; Hogg, J.C. The human bone marrow response to acute air pollution caused by forest fires. Am. J. Respir. Crit. Care Med 2000; 161:1213-7.

93. Eeden SF, Tan WC, Suwa T, et al. Cytokines involved in the systemic inflammatory response induced by exposure to particulate matter air pollutants $\left(\mathrm{PM}_{10}\right)$. Am J Respir Crit Care Med 2001; 164: 826-30

94. Greenburg L, Jacobs MB, Droletti BM, Field F, Braverman MM. Report of an air pollution incident in New York City, 1953. Public Health Reports 1962; 77: 7-16.

95. Duclos P, Sanderson LM, Lipsett M. The 1987 Forest Fire Disaster in California: assessment of emergency room visits. Arch. Environ. Health 1990; 45: 53-8.

96. Chew FT, Ooi BC, Hui JK, Saharom R, Goh D Lee BW. Singapore's haze and acute asthma in children. Lancet 1995; 346:1427

97. Long W, Tate RB, Neuman M, Manfreda J, Becker AB, Anthonisen, NR. Respiratory symptoms in a susceptible population due to burning of agricultural residue. Chest 1998; 113:351-7.

98. Rothman N, Ford DP, Baser ME, Hansen JÁ, O’Toole T, Tockman MS, Strickland PT. Pulmonary function and respiratory symptoms in firefighters. J. Occup. Med 1991; 33:1163-7.

99. Liu D, Tager Ira B, Balmes JR, Harrison RJ. The effect of smoke inhalation on lung function and airway responsiveness in wildland fire fighters. Am. Rev. Respir. Dis 1992; 146:1469-73

100.Reinhardt T, Ottmar R. Smoke exposure among wildland firefighters: A review and discussion of current literature, United States Department of Agriculture, Forest Service. Pacific Northwest Res. Station, 1997.

101. Betchley G, Koening JQ, Van Belle G, Checkoway H, Reinhardt T. Pulmonary function and respiratory symptoms in forest firefighters. Am. J. Ind. Med 1997; 31:503-9
102.Böhm G M, Saldiva PHN, Pasqualucci CA, Massad E, Martins MA, Zin WA, Cardoso WV, Criado PMP, Komatsuzaki M, Sakai RS, Nigri EM, Lemos M, Capelozzi VD, Crestana C, Silva R. Biological effects of air pollution in Sao Paulo and Cubatão. Environ. Res 1989; 49:20816.

103.Saldiva PHN, King M, Delmonte VLC, Macchione M, Parada MAC, Daliberto ML, Sakai RS, Criado PMP, Silveira PLP, Zin WA, Böhm GM. Respiratory alterations due to urban air pollution: an experimental study in rats. Environ. Res 1992; 57:19-33.

104.Lemos M, Lichtenfels AJFC, Amaro Jr, E, Macchione M, Martins MA, King M, Böhm GM, Saldiva PHN. Quantitative patology of nasal passages in rats exposed to urban levels of air pollution. Environ. Res 1994; 66:87-95.

105.Saldiva PHN, Massad E, Caldeira MPR, Calheiros DF, Saldiva CD, Nicolelis MAL, Böhm GM. Pulmonary function of rats exposed to ethanol and gasoline fumes. Braz. J. Med. Biol. Res 1985; 18:573-7

106.Massad E, Böhn GM, Saldiva PHN. Ethanol fuel toxicity. In: CORN, M., Handbook of hazardous materials. New York, Academic Press 1993; 265-75.

107.Cetesb. Superintendência de Qualidade Ambiental. Avaliação da qualidade do ar em Araraquara, 1986. São Paulo, CETESB, 1986.

108.Cetesb. Departamento de Qualidade Ambiental. Resumo dos estudos em locais influenciados diretamente pelas queimadas de cana. São Paulo, CETESB, 1999. [Memorando].

109.Franco AR. Aspectos epidemiológicos da queimada de canaviais na região de Ribeirão Preto. Centro de Estudos Brasileiros, Ribeirão Preto, 31/03/1992

110. Arbex MA, Bohn GM, Saldiva PHN, Conceição GMS, Pope AC, Braga ALF. Assesment of the effects of sugar cane plantation burning on daily counts of inhalation therapy. J of Air Waste Manag Assoc. 2000; 50: 1745-9

111.Arbex MA. Avaliação dos efeitos do material particulado proveniente da queima da plantação de cana-de-açúcar sobre a morbidade respiratória na população de Araraquara-SP. São Paulo. 188 p. Tese (Doutorado)Faculdade de Medicina, Universidade de São Paulo, 2002

112. Lara LBLS. Caracterização química da precipitação na Bacia do Rio Piracicaba: variabilidade espacial e temporal. 80 p. Tese (Doutorado)- Centro de Energia Nuclear na Agricultura, Universidade de São Paulo, 2000

113. Cançado JED. A poluição atmosférica e sua relação com a saúde humana na região canavieira de PiracicabaSP. São Paulo. 201 p. Tese (Doutorado)-Faculdade de Medicina, Universidade de São Paulo, 2003

114. American Lung Association. Selected key studies on particulate matter and health: 1997-2001. Disponivel na Internet: < http: // www.lungusa.org >. Acesso em: março de 2003. 